\title{
Ecoturismo e gestão participativa em Áreas Protegidas: o caso da Floresta Nacional do Tapajós (PA)
}

\author{
Ecotourism and participatory management in Protected Areas: \\ the case of the Tapajos National Forest (PA), Brazil
}

\section{Rafaella Soares Espínola, Vivian Maitê Castro}

\section{RESUMO}

O desenvolvimento do ecoturismo em áreas protegidas tem provocado grande discussão em relação ao seu planejamento, sustentabilidade e viabilidade em aliar conservação ambiental e retorno econômico. Todavia, para que o turismo em ambientes naturais possa ser viável, as unidades de conservação devem normatizar a atividade bem como planejá-la em seus planos de manejo, pois estes auxiliam na gestão ambiental da área e na minimização dos impactos negativos oriundos do ecoturismo. Neste contexto, o presente artigo objetiva analisar o ecoturismo praticado em uma das comunidades ribeirinhas da Floresta Nacional do Tapajós, Pará, Unidade de Conservação de uso sustentável criada em 1974. Como procedimento metodológico adotou-se o método qualitativo, pautado na revisão bibliográfica e nas visitas de campo com realização de entrevistas não estruturadas, semi-estruturadas e auxílio da técnica da observação participante. Os resultados encontrados mostram que a comunidade de Maguari constituiu-se ao redor de sua associação comunitária, que administra e organiza as atividades de ecoturismo praticadas na área, configurando-se, desta forma, em uma gestão participativa, onde a comunidade participa efetivamente de todo o processo de planejamento, execução e monitoramento da atividade. Concluiu-se que a promoção do ecoturismo em áreas protegidas passa pela necessidade da gestão participativa envolvendo os dois atores principais, poder público e comunidade local, de forma contínua e pautada nos interesses da comunidade receptora, que é o ator executor da atividade turística.

PALAVRAS-CHAVE: Ecoturismo; Áreas Protegidas; Gestão Participativa. 


\begin{abstract}
The ecotourism development in protected areas has provoked argument about the planning, sustainability and feasibility of environmental conservation and economic returns together. However protected areas should establish its rules as well as arrange it in their own management plan to the tourist activity in natural environments may be feasible because they will help in the environmental management of the area and also it will minimize the negative impacts from the ecotourism. In this context, this paper aims to analyze the ecotourism practiced in one of the riversides communities of the Tapajos National Forest, Pará, a Conservation Unities with sustainable use since 1974. This research adopted in the methodological procedure the qualitative method based on the literature review and in field activities with unstructured and semi -structured interviews, aided by point of view of participant. The results show that the Maguari community is based on their own association which manages and organizes the ecotourism activities in the area, becoming thus, a participatory management, where the community participates effectively in all the process of planning, implementation and monitoring the tourism activity. It was concluded that the development of ecotourism in protected areas should have a participatory management involving the two main actors: the government and local community on an ongoing basis and also based on the interests of the community which is the executor of tourism activities.
\end{abstract}

KEYWORDS: Ecotourism, Protected Areas, Participatory Management .

\title{
Introdução
}

A atividade turística é um fenômeno mundial com proporções grandiosas. Segundo dados da Organização Mundial do Turismo (OMT), o número de turistas internacionais passou de cerca de 480 milhões em 1995 para 842 milhões em 2006. No Brasil, de acordo com o Ministério do Turismo, o total de desembarques internacionais de passageiros, incluindo brasileiros em retorno do exterior, chegou ao número de 6.367.179 passageiros em 2006.

O turismo envolve diferentes programas, projetos e produtos de diversos atores e segmentos da economia e da sociedade, e, portanto, deve ser pensado de forma integrada. No sistema turístico, existe uma dinâmica de interesses e benefícios entre os diferentes atores envolvidos (governo, comunidades, áreas protegidas, setor privado, entre outros), que nos alerta para a complexidade do seu planejamento e instigam estudos aprofundados quanto ao seu desenvolvimento, formas e modelos de implementação.

Dentro desse contexto, o turismo pode ser classificado de acordo com alguns critérios específicos, como os interesses dos visitantes, o volume do fluxo, a proce- 
dência dos visitantes ou a frequência da viagem. Um desses segmentos, que está em constante expansão mundialmente, é o ecoturismo, que de acordo com a Embratur (1994, s/p):

É um segmento da atividade turística que utiliza, de forma sustentável, o patrimônio natural e cultural, incentiva sua conservação e busca a formação de uma consciência ambientalista através da interpretação do meio ambiente, promovendo o bem estar das populações envolvidas.

O Ecoturismo passou a destacar-se como um segmento forte e promissor nas últimas décadas, impulsionado pelo crescimento dos conglomerados urbanos, que provocam problemas como o trânsito caótico, a ocupação irregular de áreas, o aumento da poluição e a consequente diminuição de áreas verdes urbanas, entre outros. Desta forma, a procura por ambientes naturais e áreas verdes como espaços de interação e busca do equilíbrio pessoal nos momentos de lazer, passou a funcionar como uma "válvula de escape" às pessoas (RUSCHMANN, 1997).

Entretanto, dependendo de como a atividade é implementada, nem sempre traz apenas as benfeitorias elucidadas nos livros e discursos políticos daqueles que acreditam que investir em turismo é lucro certo e a solução de muitos problemas que se arrastam há tempos. A chamada indústria do turismo, que aplica um modelo de implementação da atividade com foco nos aspectos mercadológicos, visando o lucro por meio do intenso fluxo de turistas - o turismo de massa - provoca impactos negativos que atingem os diversos setores relacionados com a atividade. Neste sentido, CarvaIho (apud FARIA, 2008, p.12) alerta que: "Enquanto se entender o turismo apenas na lógica do crescimento econômico, e não como uma possibilidade de troca humana respeitosa e uma ampliação mútua do convívio, ele será desencantado".

$\mathrm{Na}$ contramão ao modelo da indústria turística, que padroniza os locais com ações imediatistas para uma implementação em curto prazo, promovendo o declínio da atividade em pouco tempo, o ecoturismo, propõe, desta forma, um formato diferente de se pensar e desenvolver a atividade turística: a partir da interação entre os visitantes e a natureza. Isto geralmente ocorre em pequenas comunidades ${ }^{1}$, onde é possível essa relação mais próxima com os visitantes e é viável administrar a atividade turística de forma participativa entre os membros deste grupo.

O Ecoturismo surge como uma alternativa de se contrapor à lógica do turismo de massa (estandardizado e predatório), e procura cada vez mais defender a proposição de roteiros personalizados, preocupados com o mínimo impacto e com grande interesse paisagístico-ecológico (SERRANO, 1997, p.19)

De acordo com Coriolano (1997, p.130), "o turismo consistente, saudável, sustentável é o que atrai pessoas desejosas de conhecer o lugar, curtir as belezas natu- 
rais, o folclore, a gastronomia e se inter-relacionar com culturas e povos diferentes".

Este segmento denominado ecoturismo busca explorar o potencial turístico com um mínimo impacto negativo sobre o meio ambiente e a cultura local, contribuindo com o desenvolvimento local por meio de uma gestão participativa da atividade. Mas o grande desafio dos planejadores de áreas protegidas consiste justamente em encontrar um equilíbrio entre a conservação ambiental e o turismo (WESTERN, 1999).

Para que o turismo se desenvolva de maneira sustentável é necessário que seu planejamento não priorize apenas seu aspecto econômico, mas também seus reflexos sociais, culturais e ambientais. Nesta lógica, buscam-se maneiras de viabilizar seu desenvolvimento, em consonância com todas as áreas que a atividade abrange.

A fim de compreender a implementação e viabilidade do ecoturismo participativo em áreas protegidas, este artigo objetiva analisar, especificamente, o ecoturismo praticado em uma das comunidades tradicionais da Floresta Nacional do Tapajós, no Pará. Para isso, primeiramente, será trabalhado o conceito de ecoturismo assim como seus aspectos positivos e negativos. E posteriormente, o caso da Floresta Nacional do Tapajós, Unidade de Conservação de uso sustentável da Amazônia Brasileira, será analisado no âmbito de uma experiência de implementação da atividade nesta região com a participação da comunidade tradicional local na concepção e gestão do ecoturismo.

Como procedimento metodológico adotou-se o método qualitativo, pautado na revisão bibliográfica e nas visitas de campo com realização de entrevistas previamente elaboradas e auxílio da técnica da observação participante.

\section{Fundamentos e princípios do ecoturismo}

É importante reconhecer que o turismo deve servir ao homem, e não o contrário.

Jost Krippendorf ${ }^{2}$

O conceito de ecoturismo é, muitas vezes, confundido com o de turismo sustentável, mas este último abrange o primeiro e é mais amplo, uma vez que o conceito de sustentabilidade pode ser aplicado em diferentes segmentos do turismo, mas para isso, Coutinho (2003, p.21) lembra que:

É necessário que a atividade seja praticada de forma racional, duradoura e que contribua para a melhoria da qualidade de vida de uma grande parte da população local. Deverá ainda visar à conservação do patrimônio natural e cultural e desenvolver atividades lucrativas que possam garantir sua manutenção a longo prazo. 
No caso do ecoturismo, a atividade é desenvolvida em áreas de relevância ambiental e a sustentabilidade (ambiental, social e econômica) é um dos princípios deste segmento. O ecoturismo também é confundido com o segmento de "turismo de natureza", que é aquele praticado em áreas com atrativos naturais relevantes, e com o segmento de "turismo de aventura", onde as atividades esportivas são realizadas na natureza (COUTINHO, 2003).

De acordo com Western (1999, p.17) as raízes do ecoturismo se encontram na natureza e no turismo ao ar livre, podendo ser definido como "a viagem responsável a áreas naturais visando preservar o meio ambiente e promover o bem-estar da população local". O ecoturismo possui um "enorme potencial econômico e conservacional", e enfatiza os recursos e o emprego da mão de obra local.

O ecoturismo requer uma abordagem multidisciplinar, bem como um planejamento rigoroso com diretrizes bem definidas, e neste contexto, os governos, as empresas privadas, as comunidades locais e organizações não governamentais possuem um papel fundamental para o estabelecimento da atividade (CEBALLOSLASCURAIN, 1999).

Uma das formas de se atingir a sustentabilidade no ecoturismo é através do fortalecimento das bases comunitárias locais, que em parceria com o setor público "é fundamental para que se promova a conservação ambiental, inclusão social, resgate e respeito à cultura tradicional, assim como a geração de renda e empregos" (COUTINHO, 2003, p.29). Porém, é preciso que exista uma vontade comum, isto é, a adesão de grande parte da comunidade para que o turismo seja desenvolvido naquela localidade, bem como perceber que tipo de crescimento a população almeja dar continuidade.

Na proposta desenvolvida por Coutinho (2003, p.29-30), o ecoturismo de base comunitária segue quatro princípios fundamentais:

- Contribuir para a conservação do meio ambiente;

- Promover, onde possível, a valorização cultural das comunidades, bem como sua capacitação para o gerenciamento participativo e de mínimo impacto dos recursos envolvidos;

- Buscar a diversificação e integração econômicas para a melhoria da qualidade de vida das comunidades.

- No desenvolvimento do ecoturismo, a integração e o equilíbrio entre conservação ambiental, respeito pela cultura local e diversificação de atividades econômicas devem ocorrer por meio de um processo participativo.

Sem a participação social das comunidades no processo de desenvolvimento do turismo, existe um grande risco de impacto social, econômico e cultural negativo, como explica Cernea (1991, apud BRANDON, 1999, p.23): 
Muitos dados revelam que projetos que prevêem a geração de benefícios econômicos, sem efetivamente encorajar a participação local na identificação, planejamento, implementação ou avaliação de atividades de desenvolvimento, estão menos aptos a propiciar benefícios para toda a comunidade.

Para Boo (1999, p.34), os impactos negativos que o turismo, incluindo o ecoturismo mal planejado, podem gerar "são a degradação do meio ambiente, as injustiças e instabilidades econômicas e as mudanças socioculturais negativas". E como benefícios potenciais do ecoturismo ele cita "a geração de receita para as áreas protegidas, a criação de empregos para as pessoas que vivem próximas a essas áreas e a promoção de educação ambiental e de conscientização sobre a conservação". O que nos sugere afirmar que o sucesso e sustentabilidade da atividade turística estão mais relacionados ao seu planejamento e gestão do que ao tipo de segmento turístico a ser adotado.

Projetos de turismo denominados de turismo comunitário pretendem proporcionar um tipo de desenvolvimento da atividade onde a comunidade participa diretamente do processo de planejamento, execução e monitoramento. Neste aspecto, a partição popular proporciona "condições para que elas mobilizem seu próprio potencial, sejam agentes sociais em vez de sujeitos passivos" (BRANDON, 1999, p.24).

É certo que a gestão participativa do turismo não é fácil de ser implementada na prática, uma vez que se exige bastante tempo para se promover discussões, estabelecer acordos em consenso e elaborar projetos. Além disso, a diversidade de necessidades e desejos no seio de uma comunidade pode dificultar e prolongar o processo de planejamento.

Swarbrooke (2000) enumera três problemas em relação ao envolvimento da comunidade nestes casos: o fato das comunidades serem raramente homogêneas, com visões conflitantes, isso não é um problema, é a realidade do ser humano, da vida em sociedade; a dominação do processo por minorias articuladas em detrimento da totalidade dos cidadãos; e o fato de nem sempre o envolvimento da comunidade representar formas mais sustentáveis de turismo.

Contudo, alguns exemplos em execução nos mostram que tais obstáculos podem ser superados com a participação e o apoio de todos os atores envolvidos, e uma política de conscientização ambiental eficiente, como é o caso da Prainha do Canto Verde, no Ceará. Neste destino turístico, a comunidade pesqueira tradicional da região auto gestiona a atividade no modelo de turismo comunitário e todos os serviços turísticos e comerciais são de propriedade e administrados pelos nativos (MENDONÇA; IRVING, 2004).

No âmbito do turismo em áreas protegidas no Brasil e no mundo, um problema preocupante refere-se à sua gestão, especialmente no que tange as normas de visitação e a capacidade de carga do ambiente, que muitas vezes não é estabelecida, ou 
ainda é desrespeitada quando este limite de visitantes é calculado, visto que muitas áreas protegidas ainda não possuem plano de manejo, sendo este, o instrumento norteador das atividades e do uso sustentável da Unidade de Conservação. Uma boa parte das unidades de conservação no Brasil não estão preparadas para a atividade turística, são administradas por pessoas não capacitadas em gestão de turismo e não dispõem de verbas para o seu planejamento (BOO, 1999).

Desta forma, para que o ecoturismo seja viável em áreas protegidas, faz-se necessário um planejamento rigoroso da atividade durante a elaboração do plano de manejo, que inclui a avaliação da capacidade de carga do ambiente, assim como o envolvimento da comunidade local e do setor público. Para a manutenção dos serviços turísticos da área é possível adquirir parcerias e convênios com prefeituras, governos, agências de auxílio internacionais, entre outros, bem como realizar concessões, instituir taxas turísticas de administração, visitação ou utilização da área. Por fim, é importante salientar que o monitoramento é essencial para que a atividade seja sustentável, atividade esta que deve ser realizada tanto por funcionários como pela própria comunidade local.

Para Ruschmann (1997), encontrar um equilíbrio entre os interesses econômicos e a conservação ambiental não é uma tarefa fácil porque seu controle depende de critérios e valores subjetivos e de uma política ambiental e turística adequada. Todavia, a sustentabilidade é uma questão fundamental e uma tendência quase obrigatória no turismo, uma vez que a atividade necessita de um meio ambiente ecologicamente equilibrado e conservado para a sua própria manutenção.

\section{O ecoturismo em Áreas Protegidas da Amazônia: o caso da Floresta Nacional do Tapajós (PA)}

O viajar parece-me um exercício proveitoso. Nele a alma exercita-se continuamente a observar coisas desconhecidas e novas, e não conheço escola meIhor para formar a vida, senão propor-Ihe a diversidade de tantas outras vidas, fantasias e usos e levá-la a saborear variedade tão perpétua das formas de nossa natureza.

Montaigne

A proteção de áreas verdes no país é uma política pública em ascensão, devido ao desenvolvimento insustentável praticado ao longo da história do Brasil em nome do crescimento e do progresso. Na década de 1970, ambientalistas determinados a fazer alguma coisa em prol do Patrimônio Natural, alertaram o país em relação à exploração desenfreada de seus recursos naturais, incitando medidas de proteção para evitar a supressão exacerbada de nossas matas.

Nos anos oitenta, o processo de redemocratização do país fortaleceu o movimento ambientalista, que ingressou e participou dos grandes eventos nacionais que 
resultaram na formulação da Constituinte, instrumento que apresenta avanços importantes na discussão acerca da preservação ambiental no país (Rocha \& Feldmann, 2006).

As Unidades de Conservação da Natureza foram organizadas a partir da regulamentação da lei federal no 9985/2000 que instituiu o Sistema Nacional de Unidades de Conservação - SNUC, estabelecendo critérios e normas para a criação, implantação e gestão das Unidades de Proteção Integral e de Uso Sustentável. A partir dessa legislação, os governos federal, estadual e municipal iniciaram o ordenamento das áreas protegidas que foram anteriormente criadas, bem como a criação de novas unidades de conservação relevantes para a manutenção dos biomas, da biodiversidade e dos serviços ambientais.

A Floresta Nacional do Tapajós, localizada no oeste do Estado do Pará, é classificada como Unidade de Conservação de Uso Sustentável. As unidades deste grupo objetivam compatibilizar a conservação da natureza com a presença de populações tradicionais e suas atividades extrativistas e de subsistência, apresentando normas que visam o uso sustentável dos recursos naturais e permitem a implementação de atividades de uso comum do público, como a atividade turística.

Com uma área estimada de 600.000ha e população de 1.100 famílias, distribuídas em 28 comunidades, a Floresta Nacional do Tapajós situa-se entre o rio Tapajós e a BR163 (Cuiabá-Santarém), ao norte faz limite com o município de Belterra e ao Sul com o município de Rurópolis, ambos no Pará. Situa-se na região do baixo Amazonas, na zona de Floresta Ombrófila Densa de Terras Baixas, abrigando amostra representativa da biodiversidade amazônica. $O$ acesso se dá via fluvial, pelo rio Tapajós, e terrestre, pela BR-163, que interliga Cuiabá a Santarém.

Esta Floresta Nacional foi criada pelo Decreto no 73.684 de 19 de fevereiro de 1974 , visando a exploração madeireira, numa época em que para este tipo de unidade, pela legislação, não poderia haver população residente. Este fato gerou diversos conflitos, que só foram resolvidos a partir de 1996, com plebiscitos e acordos entre comunidades e os órgãos ambientais competentes. Foi a primeira a constituir um Conselho Consultivo nos moldes da lei federal do SNUC, tornando-se uma experiência piloto de gestão participativa de florestas públicas. Sua oficialização deu-se em 2001, por meio da portaria 84/01, e em 2004, com a mudança do regimento interno, o conselho passou a contar com 30 membros, sendo $40 \%$ representantes das comunidades tradicionais, $30 \%$ de organizações da sociedade civil e $30 \%$ de entidades governamentais.

A Unidade de Conservação possui Plano de Manejo estabelecido, elaborado em 2003-2004, o qual determinou as áreas permitidas à visitação, que são as seguintes: Área Populacional, Área de Manejo Florestal Madeireiro, Área de Manejo Florestal não-madeireiro, Corredor Ecológico e Área Administrativa. Além da visitação turística, a unidade conta com um programa de manejo florestal de madeira.

Por ser uma área de grande representatividade do bioma amazônico, o turismo 
surge como atividade econômica possível de aliar a conservação da natureza e a geração de renda para as comunidades locais (SANSOLO, 2006).

No caso de comunidades inseridas em áreas protegidas, como por exemplo, a comunidade Maguari, que se situa na Floresta Nacional do Tapajós e será abordada mais adiante como estudo de caso deste artigo; a gestão da atividade turística e o lucro gerado devem ser organizados pela própria comunidade, que assim pode participar ativamente do processo de desenvolvimento, implementação e execução da atividade turística, direcionando os recursos advindos para suprir necessidades e melhorias comunitárias, objetivando uma melhor qualidade de vida de seus membros.

\begin{abstract}
Participar é um ato de livre escolha, uma ação de liberdade, é uma decisão de cada um. Assim, quando alguém decide participar, mobiliza sua vontade para agir em direção aquilo que definiu como objetivo e passa a se sentir responsável. Quando essa compreensão é coletiva, mobiliza grupos sociais capazes de mudar a realidade (CORIOLANO, 2003, p. 34).
\end{abstract}

Milton Santos (1998, p. 43) já repetia em seus livros e na imprensa falada que "o que globaliza separa; e o que é o local, permite a união; além de ser somente possível humanizar a partir do locaf". A proposta de ecoturismo sob a base comunitária foca-se justamente nas diferenças e peculiaridades de pequenas comunidades que possuem características ainda "desglobalizadas", e cultuam costumes e hábitos tradicionais, situando-se à margem das tendências nacionais e mundiais. Ainda segundo Santos (1998, p.44), trata-se da "reconstituição de uma humanidade organizada em torno de comunidades que se reconhecem internamente, mas que também interagem, comunicam com o resto do mundo, participam de forma organizada de espaços mais amplos".

Estas comunidades habitam áreas naturais de relevante beleza, que junto aos aspectos culturais, são atrativos turísticos capazes de mobilizar viajantes. Um grande nicho de turistas nacionais e estrangeiros buscam esse perfil de viagem, onde a natureza, o intercâmbio cultural e a vivência em comunidades tradicionais são o foco da experiência turística.

(...) não é que o ser humano agora seja menos solidário, é que ninguém se solidariza com o anonimato. A humanização do desenvolvimento, ou a sua re-humanização, passa pela reconstituição dos espaços comunitários. O próprio resgate dos valores e a reconstrução da dimensão ética do desenvolvimento exigem que para o ser humano o outro volte a ser um ser humano, um indivíduo, uma pessoa com os seus sorrisos e suas lágrimas. (DOWBOR, 1998, p. 25). 
Além de promover a valorização do lugar, das pessoas e suas culturas, a base local se mobiliza e se une diante do desafio de gerir a atividade turística, ganhando forca e poder decisório frente à indústria do turismo e suas padronizações. "A tendência é sempre criar padrões. Padrões que, na verdade, empobrecem senão anulam a diversidade cultural brasileira" (BANIWA apud FARIA, 2006, p. 69).

O reconhecimento da cultura local, a elevação da auto-estima, o orgulho e o fortalecimento da associação comunitária são algumas das metas que podem ser alcançadas com este modelo de turismo, que busca valorizar pessoas, lugares e modos de vida que não estão integrados ao modelo convencional da indústria turística.

No caso da Floresta Nacional do Tapajós, o principal diferencial do ecoturismo lá praticado é a oportunidade de conhecer a floresta amazônica e interagir com a comunidade local ribeirinha, compartilhando conhecimentos e experiências, de uma maneira que vai além da compra de um serviço. A comunidade passa a ser um atrativo e o turista acaba tornando-se parceiro, e a relação de troca, partiIha, convivência e aprendizagem são os fatores principais que os impulsionam. A viagem passa a ser educativa, estimulante da curiosidade, da interação com a natureza, do crescimento pessoal e cultural.

\section{Estudo de caso na Floresta Nacional do Tapajós: a comunidade Maguari}

O ecoturismo na Amazônia tornou-se um produto turístico de alto valor de mercado, com infra-estrutura diferenciada, hotéis ecológicos e hotéis de selva de luxo, além de pacotes estruturados para conhecer a fauna do bioma amazônico, até porque avistar animais naturalmente na floresta é bastante difícil na Amazônia. Com a premissa de envolver a comunidade local na atividade turística e promover um ecoturismo de menor impacto no ambiente natural, o destino Amazônia passou a ser focado num mercado de alto poder aquisitivo, principalmente para turistas proveniente de outros países. "O exemplo do Amazonas está consideravelmente bem distante de proporcionar o envolvimento das populações locais e gerar os benefícios desejados pela sociedade" (LOBATO NETO, 1999, p. 148).

Buscando estudar e encontrar um outro ecoturismo na Amazônia, pautado nos princípios da participação coletiva da comunidade local no processo decisório de planejamento, implementação e execução da atividade turística, diferente deste modelo de indústria turística comumente encontrado e descrito acima; este estudo de caso objetivou analisar a experiência de uma comunidade pertencente à Floresta Nacional do Tapajós, a comunidade Maguari. Situada próxima à cidade de Santarém, com acesso terrestre, esta comunidade é uma das três que recebem turistas de maneira contínua, de um total de 28 comunidades existentes na Unidade de Conservação. 
Os procedimentos metodológicos da aplicação da pesquisa de campo em Maguari pautaram-se em análise prévia da literatura, entrevistas não estruturadas com viajantes brasileiros e estrangeiros que chegavam no porto de Santarém (com destinos de viagem variados, e não apenas aqueles que iam visitar a Floresta $\mathrm{Na}$ cional do Tapajós), entrevistas semi-estruturadas com membros da comunidade Maguari e Jamiraguá, visitação aos atrativos gerenciados pela associação comunitária, estadia em casa de família com alimentação local, providenciada pela mesma e a observação participante da atividade turística.

Segundo os moradores locais, a iniciativa de implementação do ecoturismo em Maguari iniciou-se em 1998, com o incentivo do Ibama. O órgão subsidiou capacitações em condução ambiental, sobrevivência na selva, primeiros socorros, salvamento, como receber visitantes e língua inglesa, bem como apresentou outras áreas protegidas nas cidades de Brasília, São Paulo, Curitiba e Rio de Janeiro, para que a comunidade pudesse analisar outras experiências para planejar seus atrativos. Após este período de capacitações e planejamento da atividade, o início das atividades de ecoturismo ocorreu no ano de 2000.

Atualmente, Maguari recebe aproximadamente 400 turistas por ano, segundo dados coletados pelo Instituto Chico Mendes de Conservação da Biodiversidade (ICMBio) na portaria de entrada da Unidade de Conservação. Os turistas são provenientes de diversos países, especialmente europeus, além de alguns brasileiros provenientes de diferentes estados do país. O ICMBio cobra uma taxa para permanência na unidade desde 1998 , cujo valor atualmente é de $R \$ 5,00$ por dia, que pode ser quitada tanto no escritório do órgão, em Santarém, como também na portaria da comunidade São Domingos, primeira da Unidade.

Os turistas que optam por pacotes turísticos comercializados nas agências de turismo receptivo existentes em Santarém, quitam essa taxa de visitação diretamente na agência. A mesma geralmente está inclusa no preço total do pacote turístico. Neste estudo de caso, optou-se pela não utilização do pacote turístico.

Em relação à estrutura de hospedagem, há poucos moradores que disponibilizam suas casas para pernoite, no entanto a comunidade em geral é beneficiada pelos recursos advindos do ecoturismo, principalmente por meio da taxa única de permanência $R \$ 7,00$ cobrada pela Associação de Moradores da Comunidade Maguari, valor que independe da quantidade de dias de permanência. A arrecadação anual proveniente dessa taxa é revertida em melhorias na saúde e educação, especialmente em relação à única escola de ensino fundamental e médio dessa comunidade e da comunidade seguinte, Jamaraquá. Além disto, os recursos ainda suprem eventuais necessidades de infra-estrutura comunitária, como construção de poços artesianos, melhorias na via de acesso e manutenção dos atrativos turísticos, neste caso as trilhas utilizadas para condução ambiental de turistas na floresta amazônica. 
A venda de artesanato, produtos alimentícios e a própria atividade de condução ambiental são outras fontes de lucros para a comunidade. A Associação de Moradores estabeleceu um sistema de rodízio entre os condutores, que devem ser moradores locais capacitados, especialmente em sobrevivência na selva, primeiros socorros e salvamento. Na época da pesquisa in loco, junho de 2011, a associação contava com 15 condutores disponíveis, supervisionados por um coordenador que organizava o rodízio e recebia os visitantes. As opções de passeios variam desde longas e curtas trilhas, à viagens com pernoite em acampamento na floresta, para os que almejam tentar observar os grandes felinos, além de passeios de barco pelo Rio Tapajós.

Segundo Sr. Abílio, um dos dirigentes da associação comunitária de Maguari e também condutor ambiental, o fluxo de turistas é bastante satisfatório e as meIhorias comunitárias advindas do turismo são visíveis, inclusive para aqueles que não se envolvem diretamente com a atividade turística, como os comerciantes de alimentos e artesanato. Segundo este morador, a maior parte da comunidade hoje vive de recursos advindos da cooperativa local de látex, da comercialização de farinha de mandioca, do artesanato e do ecoturismo. Assim, a diversidade de atividades proporciona diferentes fontes de renda, que junto ao ecoturismo, promovem melhorias comunitárias.

Entretanto, um problema apontado pela comunidade, que preocupa a associação e causa desconforto na relação com os turistas é a existência de duas taxas de permanência, uma estabelecida pela associação de moradores (taxa única por permanência de $R \$ 7,00)$ e a outra pertencente ao ICMBio ( $R \$ 5,00$ por dia de estadia na Unidade de Conservação). Apesar de terem propósitos e destinações distintas, a taxa dupla é alvo de muitos questionamentos por parte dos turistas, que se incomodam em pagar para permanecer em um mesmo local duas vezes.

Apesar de a gestão participativa da Unidade de Conservação estar implementada desde a criação do Conselho Consultivo, em 2001, a dupla taxação provoca transtornos à comunidade e aos turistas, evidenciando um conflito de gestão entre a associação de moradores e o órgão governamental gestor. A taxa de visitação cobrada pelo governo é praticada em várias unidades de conservação da natureza, variando seu valor, porém com a destinação voltada aos cofres públicos. Já a taxa da comunidade é revertida em benfeitorias para ela mesma, e estas, por consequência, acabam melhorando a estrutura oferecida aos turistas.

Segundo a opinião dos moradores coletada na pesquisa de campo, em situações desconfortáveis com os turistas, a associação deixa de cobrar a taxa de permanência, perdendo esse recurso financeiro. Ainda segundo eles, deve-se repensar essa taxa diária cobrada pelo ICMBio, sugerindo-se tanto a diminuição do valor, quanto a veiculação de informações e sinalizações na Unidade de Conservação explicando a diferença entre as duas taxas e a destinação de ambas, para 
que os turistas as compreendam.

Em relação aos atrativos da comunidade Maguari, a associação de moradores possui alguns passeios e roteiros pré-estabelecidos, que são negociados diretamente com o condutor ambiental. As opções incluem caminhadas de curta e longa distância em áreas conservadas da Unidade de Conservação, com explicações detalhadas da fauna e flora, sua utilização medicinal e até cosmética, realizada de maneira empírica pelos condutores da associação, moradores antigos e bem habituados à floresta.

O ponto mais alto das caminhadas oferecidas em Maguari é a visitação às grandes Sumaúmas, (Ceiba pentandra (L.) Gaertn, Samaúma ou Sumaomeira, na linguagem popular local), conhecida como a maior árvore da Amazônia, pois a espécie pode alcançar 100 metros de altura. Há uma trilha com três exemplares em seu percurso total, com alturas e larguras diferentes, sendo o último deles, após 09 quilometros de caminhada, a Samaúma Vovó, uma árvore com idade estimada em 900 a 1000 anos.

Outras opções de conhecer Maguari são os passeios de barco pelo rio Tapajós, com direito a observação da pesca artesanal realizada pelos moradores, onde alguns ainda utilizam o arco e a flecha para afastar os botos-cor-de-rosa das suas redes. E, há ainda a possibilidade de visitação à casa de outros moradores, tanto para mostrar e comercializar a fabricação de alimentos, a exemplo da farinha de mandioca e do mel de abelhas nativas, como também para possibilitar o acesso ao artesanato feito pelos moradores.

Tomar banho de rio, brincar com as muitas crianças com traços indígenas da comunidade, que possuem uma rotina pautada nas aulas na escola comunitária, nas brincadeiras populares e em muito banho de rio, além de poder caminhar pela floresta e assistir a uma forte chuva da janela, que rapidamente provoca uma roda de conversa com contação de lendas e estórias. É esse o ecoturismo praticado na comunidade Maguari. Um momento de troca cultural e vivência com a natureza, pautada na gestão participativa dos moradores e no fortalecimento da associação comunitária de Maguari, que realiza a autogestão do turismo e gerencia os recursos advindos com a atividade para melhorias locais, promovendo assim 0 bem estar de toda a comunidade.

\section{Considerações finais}

O fortalecimento do ecoturismo sob a base comunitária, focando-se na tradição e cultura local, aliado a um planejamento adequado, podem minimizar os impactos indesejáveis ocasionados pelo turismo. O planejamento e a gestão do turismo em áreas protegidas, especialmente envolvendo comunidades tradicionais, devem propor a participação destas nas discussões e esclarecimento de dúvidas a- 
cerca da atividade turística, valorizando a identidade cultural e territorial, e permitindo assim que os envolvidos possam decidir sobre seu futuro (FARIAS, 2009). As comunidades, ao assumirem seu papel no planejamento, operação, fiscalização e desenvolvimento do turismo, podem contribuir para que o mesmo torne-se fonte de oportunidades, aliando geração de renda à proteção da natureza.

Desta forma, o modelo de ecoturismo sob a base comunitária focado nas comunidades tradicionais evidencia novas possibilidades turísticas em áreas protegidas no Brasil. Esse fato pode propiciar um avanço nos modelos de implantação do turismo no país, através de propostas que privilegiem o meio ambiente e a cultura das comunidades tradicionais.

No caso da Floresta Nacional do Tapajós, no Pará, o ecoturismo é realizado de maneira satisfatória, atendendo os principais princípios do segmento, e com a total participação da comunidade tradicional em todo o processo de planejamento, execução e fiscalização da atividade, servindo de exemplo para outras áreas protegidas.

Assim, concluímos que a promoção do ecoturismo em áreas protegidas passa pela necessidade da gestão participativa envolvendo, sobretudo, os dois atores principais, poder público e comunidade local, de forma contínua e pautada nos interesses da comunidade receptora, que é o ator executor da atividade turística.

\section{Referências bibliográficas}

BRASIL, 2000. Sistema Nacional de Unidades de Conservação (SNUC). Lei N ${ }^{0}$ 9.985, de 18 de julho de 2000.

BUBER, M. Sobre comunidade. São Paulo: Perspectiva, 2008.

CORIOLANO, L.N.M.T. Do local ao Global: o turismo litorâneo cearense. São Paulo: Papirus, 1998.

CORIOLANO, L.N.M.T A Prainha do Canto Verde: Locus de Resistência e Turismo Comunitário. Fortaleza: EDUECE, 2003.

COUTINHO, P. (Org). Sociedade e ecoturismo: na trilha do desenvolvimento sustentável: Como diferentes atores sociais podem, de forma, participativa, elaborar planos estratégicos de conservação e geração de renda. São Paulo: Peirópolis, 2003.

Empresa Brasileira de Turismo. Diretrizes para uma política nacional de ecoturismo. Brasília - DF, 1994.

DOWBOR, L. A Reprodução Social: Propostas para uma Gestão Descentralizada. 1998. Disponível em: <www.reggen.org.br>. Acesso em 26 de março de 2012. 
FARIA, H.; LIMA, R. Fomento, Difusão e Representação das Culturas Populares. Brasília: Ministério da Cultura, 2006.

FARIAS, I. F. Ecoturismo, cultura e participação: gestão do território indígena do Alto Rio Negro. In: BARTHOLO, R. et al.(orgs.) Turismo de base comunitária: diversidades de olhares e experiências brasileiras. Rio de Janeiro: letra e imagem, 2009.

IBAMA. Plano de Manejo da Floresta Nacional do Tapajós, 2005.

MENDONÇA, T.C.; IRVING, M.A. Turismo de base comunitária: a participação como prática no desenvolvimento de projetos turísticos no Brasil - Prainha do Canto Verde, Beberibe (CE). Caderno Virtual de Turismo. V.4, ㄲo4, 2004. Disponível em:<http://www.ivt.coppe.ufri.br/caderno/index.php? journal=caderno\&page=article\&op=view\&path\%5B\%5D=66>. Acesso: 30/04/2012.

NETO, O.L. Ecoturismo: o exemplo do Amazonas. In: FIGUEIREDO, Silvio Lima (org). O Ecoturismo e a questão ambiental na Amazônia. Belém: UFPA/NAEA, 1999.

ROCHA, A.A.; FELDMANN, F. A Mata Atlântica é aqui. E daí? História e luta da Fundação SOS Mata Atlântica. São Paulo: Terra Virgem, 2006.

RUSCHMANN, D. Turismo e planejamento sustentável: A proteção do meio ambiente. Campinas/SP: Papirus, 1997.

SANSOLO, D.G. Centralismo e Participação na proteção da natureza e desenvolvimento do turismo no Brasil. In: IRVING, Marta de Azevedo. Áreas Protegidas e Inclusão Social: Construindo Novos Significados. Rio de Janeiro: Aquarius, 2006.

SERRANO, C.; BRUHNS, H.T. (orgs). Viagens à natureza: turismo, cultura e ambiente. Campinas, SP: Papirus, 1997.

SWARBROOKE, J. Turismo sustentável: conceitos e impacto ambiental. Vol.1. São Paulo: Aleph, 2000.

WESTERN, D. Como definir o ecoturismo. In: LINDENBERG, K.; HAWKINS, D.E. (orgs.) Ecoturismo: um guia para planejamento e gestão. São Paulo: Ed Senac, 2005.

Notas:

${ }^{1}$ Por comunidade entendemos "a ligação que se desenvolveu mantida internamente por propriedade comum (sobretudo de terra), por trabalho comum, costumes comuns, fé comum" (BUBER, 2008, p.50). 
${ }^{2}$ Sociólogo alemão que aprofunda seus estudos em entender a alteração de valores na sociedade industrial moderna, que passou a usar o turismo como forma de se afastar do cotidiano. Ele defende que a atividade turística deve ser um momento de aprendizado e de experiência, com o objetivo de redescobrir o próprio cotidiano enquanto fora dele, para modificá-lo ao regressar a rotina habitual.

Rafaella Soares Espínola: Universidade Federal da Paraíba, João Pessoa, PB, Brasil.

Email: rafaellafr@hotmail.com

Link para o currículo Lattes: http://lattes.cnpq.br/4751012040434788

Vivian Maitê Castro: Universidade Federal da Paraíba, João Pessoa, PB, Brasil. Email: vivianmaite@hotmail.com

Link para o currículo Lattes: http://lattes.cnpq.br/3778279718166284

Data de submissão: 27 de março de 2012

Data de recebimento de correções: 04 de maio de 2012

Data do aceite: 05 de maio de 2012

Avaliado anonimamente 